\title{
CRITICAL ISSUES IN MEASURING THE MECHANICAL PROPERTIES OF HARD FILMS ON SOFT SUBSTRATES BY NANOINDENTATION TECHNIQUES
}

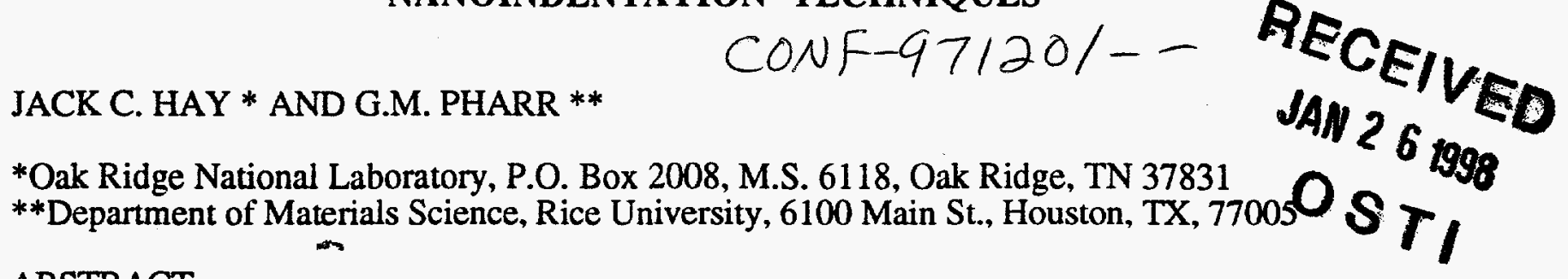
ABSTRACT

This study explores the difficulties encountered when using conventional nanoindentation techniques to measure the Young's modulus and hardness of hard films on soft substrates. In general, the indentation measurement of film/substrate systems is affected by four material properties: the Young's modulus and hardness of the film, and the Young's modulus and hardness of the substrate. For the particular case of a hard film on a soft substrate, there is a tendency for the material around the hardness impression to sink-in which results from the large difference in yielding of the two materials. In this study, a 'model' system consisting of NiP on annealed $\mathrm{Cu}$ was used to explore the behavior. This system is interesting because the film and substrate have simmilar Young's moduli, minimizing the elastic behavior as a variable. In contrast, the hardness of NiP is approximately $7-8 \mathrm{GPa}$, and that of the annealed copper is less than $1 \mathrm{GPa}$, providing a factor of 10 difference in the plastic flow characteristics. Experimental results indicate that standard arfalytical methods for determining the contact depth, hardness and Young's modulus do not work well for the case of a hard film on a soft substrate. At shallow contact depths, the measured indentation modulus is close to that of the film, but at larger depths sink-in phenomena result in an overestimation of the contact area, and an indentation modulus which is less than the Young's modulus of both the film and substrate. Atomic force microscopy (AFM) and scanning electron microscopy (SEM) provide critical details of the physical processes involved, and illustrate how the standard data analyses overestimate the true contact area.

\section{INTRODUCTION}

Nanoindentation is maturing as an important analytical method for evaluating the Young's modulus and hardness of monolithic and composite materials, including film/substrate systems [13]. The technique is particularly useful in the study of thin films [4-8], since it is often possible to evaluate film properties without removing the film from the substrate. There is, however, an experimental limit to making practical substrate-independent measurements in ultrathin films. One rule of thumb, which is based largely on empirical observations, states that film properties can be measured independent of the substrate so long as the total indentation depth is less than $10 \%$ of the film thickness. For many films, this rule does not restrict the measurement; however, when films are in the range of $100 \mathrm{~nm}$ to $200 \mathrm{~nm}$ thick, experimental difficulties of making accurate measurements at indentation depths of $10 \mathrm{~nm}$ to $20 \mathrm{~nm}$ impose severe limitations. For systems where the indentation measurement is affected by the substrate properties, it may still be possible to determine the film properties if the substrate properties are known. Several experimental and theoretical treatments [7,9-12] consider the relationships between the film and substrate properties and the indentation property measurement.

The present study examines the case of a hard film deposited on a soft substrate and the problems associated with measuring the properties of the film by nanoindentation methods. One important characteristic of making indentations in these systems is the tendency for the material around the indenter to sink-in. The displacements in the film are largely elastic, and when plasticity commences in the substrate, the substrate material beneath the indenter flows. The Sneddon solution [13], which forms the basis for the methods used in determining the contact depth and contact area from experimental data, does not account for the sink-in phenomenon. The result is that the Oliver-Pharr [3] method of determining the contact depth overestimates the effective contact depth and the actual contact area. The errors incurred in evaluating the contact area percolate through the analysis into the hardness and Young's modulus through the relations,

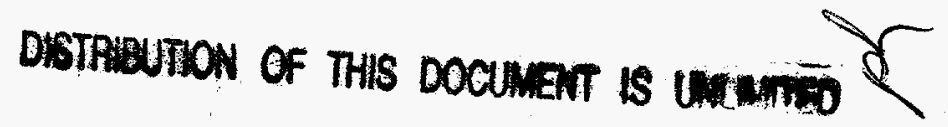




$$
H=\frac{P_{\max }}{A} \text {, }
$$

and

$$
\text { a } \quad E_{\text {eff }}=\frac{E}{\left(1-v^{2}\right)}=\frac{\sqrt{\pi}}{2} \frac{S}{\sqrt{A}},
$$

where $H$ is the hardness, $P_{\max }$ is the peak indentation load, $A$ is the projected contact area, $E$ is the Young's modulus, $v$ is Poisson's ratio for the indented material, and $S$ is the elastic contact stiffness. Therefore, when the contact area is overestimated, the hardness is underestimated by a factor of similar scale, and the Young's modulus is underestimated by a factor which scales as the square root of the error in contact area.

\section{EXPERIMENTAL}

The system selected for these exploratory studies was NiP on soft annealed copper. This is a 'model' system in which the hardness of the film $(7-8 \mathrm{GPa})$ and the hardness of the substrate $(0.75 \mathrm{GPa})$ vary by roughly a factor of ten. An important consideration in selecting these materials was the similarity of their elastic properties, which minimizes Young's modulus mismatch as a possible factor im the interpretation of results. The Young's modulus of copper is about $129 \mathrm{GPa}$ and that of the NiP is about $160 \mathrm{GPa}$.

High-purity (99.999\%) copper disks $19 \mathrm{~mm}$ in diameter and $10 \mathrm{~mm}$ in height were used as substrate materials. The samples were rough ground with silicon carbide paper to a 600 grit, achieving nearly parallel faces. A subsequent vacuum anneal at $350^{\circ}$ for one hour resulted in a very soft copper with grains as large as $1 \mathrm{~mm}$. The oxidized surface layer was then removed by light grinding using fine grit silicon carbide papers, and final polishing resulted in a near-mirror finish. An electroless NiP plating process (MacDermid, Inc., Bay City, MI) was used to produce hard amorphous NiP films of two thicknesses, $700 \mathrm{~nm}$ and $10 \mu \mathrm{m}$, on the copper coupons.

The Young's modulus and hardness of the $\mathrm{NiP} / \mathrm{Cu}$ system were studied using a Nanoindenter II (Nano Instruments, Inc., Oak Ridge, TN) which is capable of accurately measuring both the indentation load and depth during an experiment. The experiments were performed to a range of peak loads with a Berkovich diamond tip, producing indentations which varied in total depth from $15 \mathrm{~nm}$ to approximately $2000 \mathrm{~nm}$. Although these depths only penetrate a fraction of the $10 \mu \mathrm{m} \mathrm{NiP}$ film, penetrations in the $700 \mathrm{~nm} \mathrm{NiP}$ film ranged from $5 \%$ to $300 \%$ of the film thickness. Thus, substrate-independent measurements of the NiP were possible in the 10 um sample, while the $700 \mathrm{~nm}$ sample allowed for the study of the substrate influences on the measured properties. The Oliver-Pharr method was used to determine the contact depth and projected contact area at each indentation load from measurable quantities including the contact stiffness, $S$, the maximum load, $P_{\max }$, and the maximum penetration depth, $h_{\max }$. The properties evaluated from the contact depth determined by the Oliver-Pharr method and Equations 1 and 2 will be defined as $E_{\text {nano }}, H_{\text {nano }}$, and $A_{\text {nano }}$. Subsequent imaging of the indentations by SEM and AFM revealed the actual contact area, $A_{\text {actual }}$, which was used with the measured stiffness and Equation 2 to obtain a second measurement of the Young's modulus, $E_{\text {actual, }}$, and hardness, $H_{\text {actual }}$. While the hardness measured from $P_{\max }$ and $A_{\text {actual }}$ is the true hardness (by definition), the Young's modulus determined from the Sneddon relationship may or may not be correct. Differences observed in the modulus and hardness evaluated from the two different area estimations are related to the manner in which the Oliver-Pharr method determines contact areas from experimental load-displacement data.

\section{RESULTS AND DISCUSSION}

To systematically study the $\mathrm{NiP} / \mathrm{Cu}$ system, baseline data for the characteristic bulk properties of both the copper substrate and the thick NiP film were first determined. One copper disk was indented at various indentation loads ranging from $0.06 \mathrm{mN}$ to $120 \mathrm{mN}$ before NiP 


\section{DISCLAIMER}

This report was prepared as an account of work sponsored by an agency of the United States Government. Neither the United States Government nor any agency thereof, nor any of their employees, makes any warranty, express or implied, or assumes any legal liability or responsibility for the accuracy, completeness, or usefulness of any information, apparatus, product, or process disclosed, or represents that its use would not infringe privately owned rights. Reference herein to any specific commercial product, process, or service by trade name, trademark, manufacturer, or otherwise does not necessarily constitute or imply its endorsement, recommendation, or favoring by the United States Government or any agency thereof. The views and opinions of authors expressed herein do not necessarily state or reflect those of the United States Government or any agency thereof. 


\section{DISCLAIMER}

Portions of this document may be illegible electronic image products. Images are produced from the best available original document. 

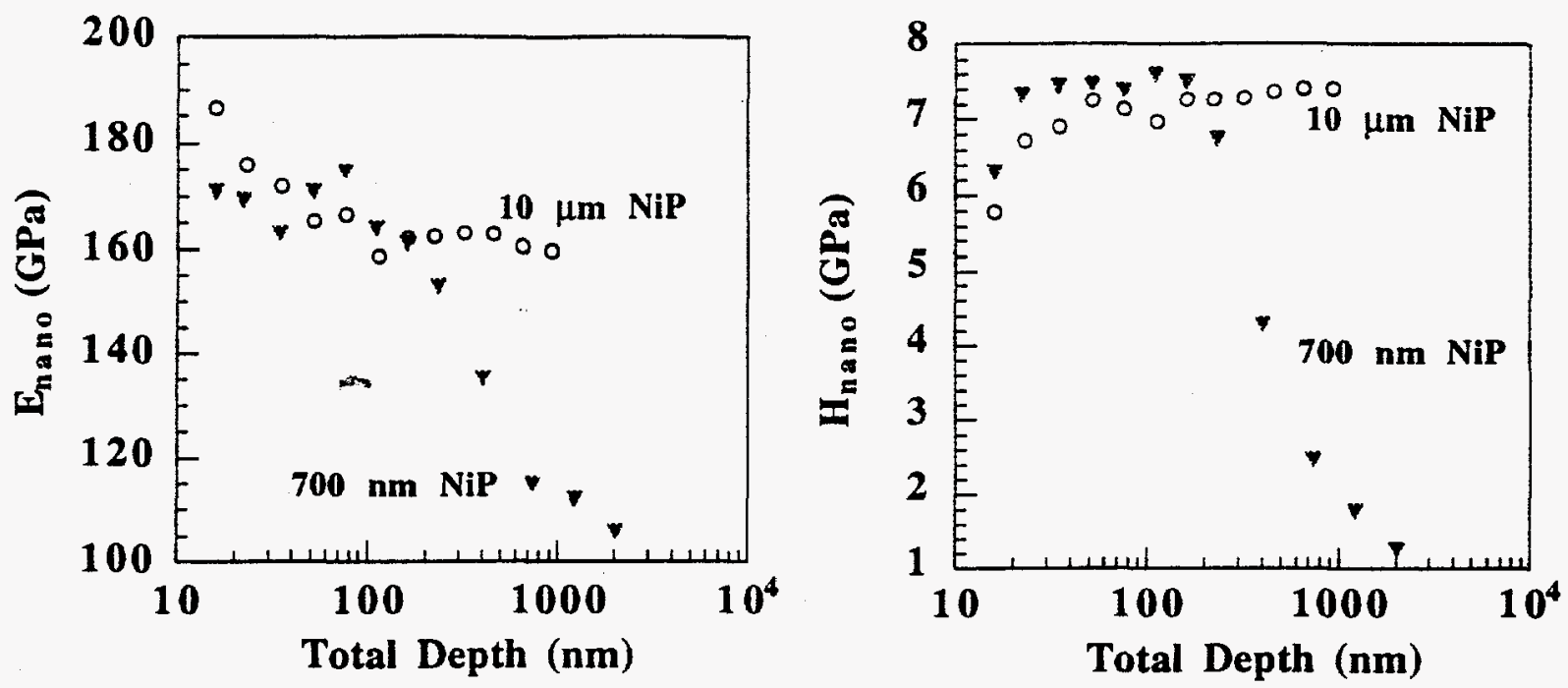

Figure 1. Young's modulus and hardness of $700 \mathrm{~nm}$ and $10 \mu \mathrm{m}$ NiP films evaluated using the Oliver-Pharr method of determining contact depth.

plating. Similar to other soft, work-hardenable materials, the copper exhibited an indentation size effect $[14,15]$, with the hardness ranging from $0.6 \mathrm{GPa}$ at a depth of $2500 \mathrm{~nm}$ to $2.25 \mathrm{GPa}$ at a depth of $23 \mathrm{~nm}$. The indentation modulus for the copper varied between $120 \mathrm{GPa}$ and $125 \mathrm{GPa}$ across the range of indentation loads used, in good agreement with the Young's modulus of polycrystalline copper, $129 \mathrm{GPa}[16]$.

To measure the properties of NiP, the $10 \mu \mathrm{m} \mathrm{NiP}$ sample was indented using the same range of peak-load indentation experiments. By making indentations shallower than $1 \mu \mathrm{m}$, one should be able to make measurements of the NiP without significant influences of the copper substrate. Figure 1 summarizes the hardness, $H_{\text {nano }}$, and Young's modulus, $E_{\text {nano }}$, for the $10 \mu \mathrm{m}$ NiP film derived from area measurements based on the Oliver-Pharr method. Except for small variations in the shallow indent range $(<40 \mathrm{~nm})$, it is interesting to note that at depths up to 2000 $\mathrm{nm}$, or $20 \%$ of the film thickness, both the hardness and Young's modulus appear to be constant, suggesting a negligible influence of the substrate.

To confirm the measurements made by the Oliver-Pharr method, the actual contact areas were measured by SEM imaging. Figure 2a presents an SEM micrograph of a hardness impression in the $10 \mu \mathrm{m}$ film made at a peak load of $120 \mathrm{mN}$. The relatively straight sides suggest that there is little pile-up or sink-in along the faces. However, the AFM height profile (Figure 2b)

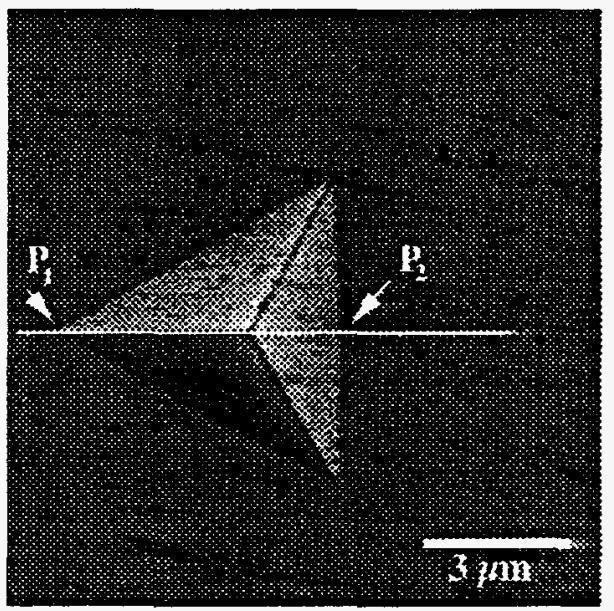

(a)

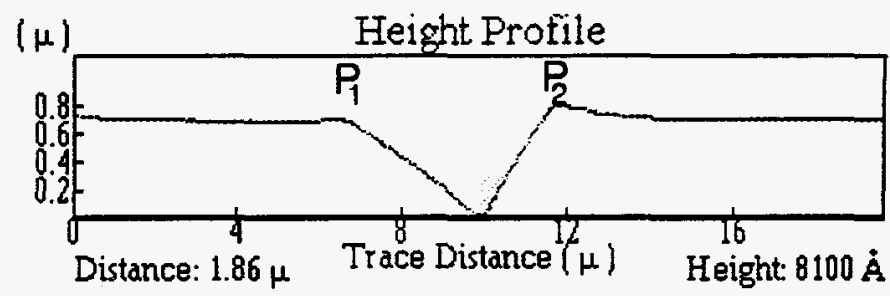

(b)

Figure 2. SEM image of a $120 \mathrm{mN}$ indentation in the $10 \mu \mathrm{m}$ NiP film. The height profile was measured by AFM and was performed along the trace illustrated in the SEM photograph. 


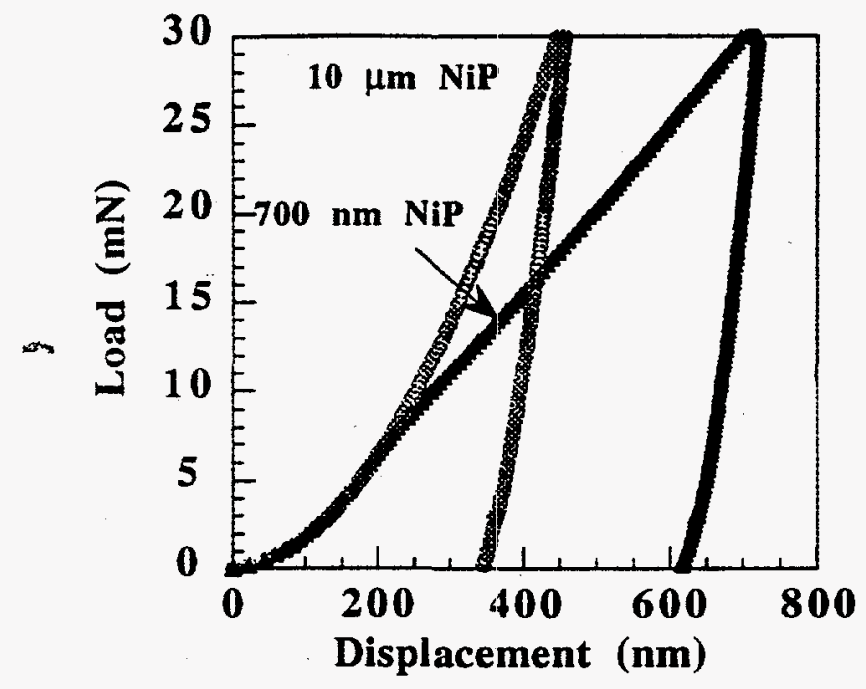

Figure 3. Load displacement curves for $30 \mathrm{mN}$ indentations in both the $700 \mathrm{~nm}$ and $10 \mu \mathrm{m} \mathrm{NiP}$ films.

along the line indicated in the SEM photograph indicates that there is, in fact, some pile-up along the faces, but aot at the corners. The pile-up increases the contact area slightly above what is predicted by the Oliver-Pharr method, resulting in an indentation modulus which is lower by approximately 3-5\%. Therefore, the real Young's modulus is probably closer to $155 \mathrm{GPa}$ than $160 \mathrm{GPa}$.

When the same indentation experiments are performed on the $700 \mathrm{~nm} \mathrm{NiP}$ film, the measured properties are affected by the copper substrate at the larger indentation depths. In Figure 3 , load-displacement data for $30 \mathrm{mN}$ indentations are presented for both the $700 \mathrm{~nm}$ and $10 \mu \mathrm{m}$ films. Based on the previous discussion, the load-displacement behavior of the $10 \mu \mathrm{m}$ film should be representative of NiP. The load-displacement behavior of the $700 \mathrm{~nm}$ film behaves like NiP up to a contact depth of $200 \mathrm{~nm}$, but at larger depths the $700 \mathrm{~nm}$ film is much more easily penetrated. The load and displacement where the transition appears is quite repeatable, appears on all of the load-displacement curves, and is independent of peak indentation load. We speculate that this transition point results from the commencement of plastic flow in the copper substrate.

The indentation moduli and hardnesses for the $700 \mathrm{~nm}$ NiP film are plotted along with the $10 \mu \mathrm{m}$ NiP data in Figure 1. In general, the properties behave in a reasonable and predictable manner. At shallow depths, i.e., before the onset of plasticity in the copper at a depth of $200 \mathrm{~nm}$, the indentation modulus and hardness tend towards the NiP properties measured in the $10 \mu \mathrm{m} \mathrm{NiP}$ film. At depths greater than $200 \mathrm{~nm}$, both the indentation modulus and the hardness decrease
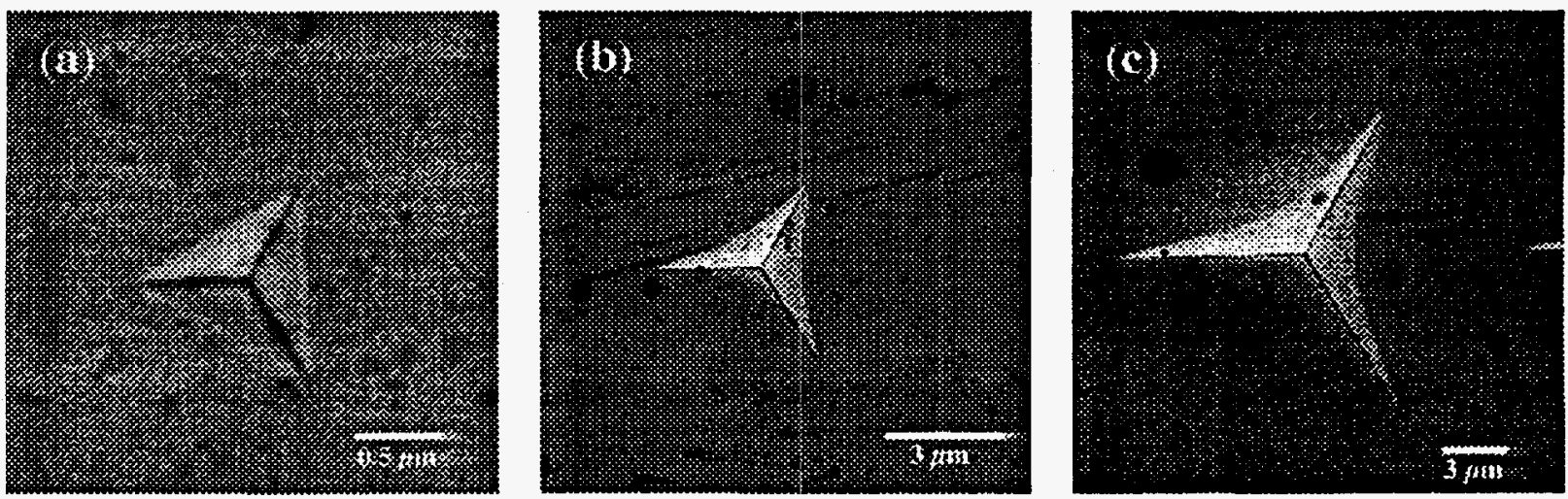

Figure 4. SEM images of (a) $4 \mathrm{mN}$, (b) $30 \mathrm{mN}$ and (c) $120 \mathrm{mN}$ indentations in the $700 \mathrm{~nm}$ NiP film. 


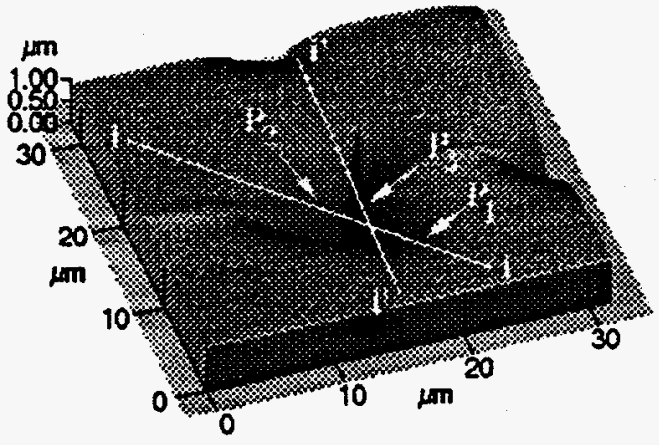

(a)

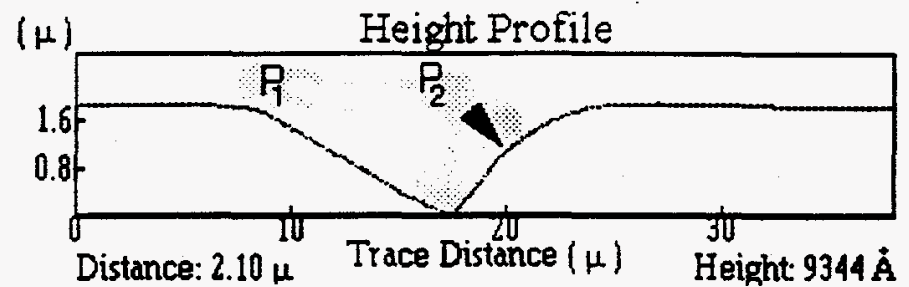

(b)

Figure 5. AFM image (a) of a $120 \mathrm{mN}$ indentation in the $700 \mathrm{~nm}$ NiP film. The height profile (b) was measured by AFM along the trace $i-i$ illustrated in (a).

towards values representative of the copper bulk. Interestingly, however, at very large contact depths the indentation modulus falls below the Young's modulus of both the NiP and copper. The deepest indentation made in the study (contact depth of $2000 \mathrm{~nm}$ ) yielded an indentation modulus of $104 \mathrm{GPa}$, which is significantly lower than the Young's modulus of either the NiP (E=155 $\mathrm{GPa})$ or copper $(\mathrm{E}=129 \mathrm{GPa})$.

The fact that the indentation modulus falls below that of the copper substrate is related to sink-in phenomena. To demonstrate the importance of sink-in, Figure 4 presents SEM images of indentation impressions in the $700 \mathrm{~nm}$ film for peak loads of $4 \mathrm{mN}, 30 \mathrm{mN}$, and $120 \mathrm{mN}$. At shallow depths, i.e., prior to point of deviation in Figure 3, the impression is indistinguishable from impressions in the $10 \mu \mathrm{m}$ film; that is, it is nearly triangular and exhibits limited pile-up or sink-in. For peak indentation loads greater than roughly $7 \mathrm{mN}$, though, plasticity presumably occurs in the substrate, resulting in sink-in. In contrast to the concave sides which bow out when there is pile-up, the convex sides associated with sink-in reduce the contact area as shown in Figure $4 \mathrm{~b}$ and $4 \mathrm{c}$. The AFM image in Figure $5 \mathrm{a}$ illustrates the manner in which the sides of the indentation sink-in for the $120 \mathrm{mN}$ indentation. Since there is little pile-up or sink-in at the corners, the Oliver-Pharr method predicts a contact area which, as determined from the SEM photographs, is represented by the corner-to-corner area. However, the actual contact area is smaller than that predicted by Oliver-Pharr. The last points of contact $\left(P_{1}\right.$ and $\left.P_{2}\right)$ between the specimen and indenter can also be observed in Figure 5b where the 'lip' is noted by one of the arrows $\left(\mathrm{P}_{2}\right)$.
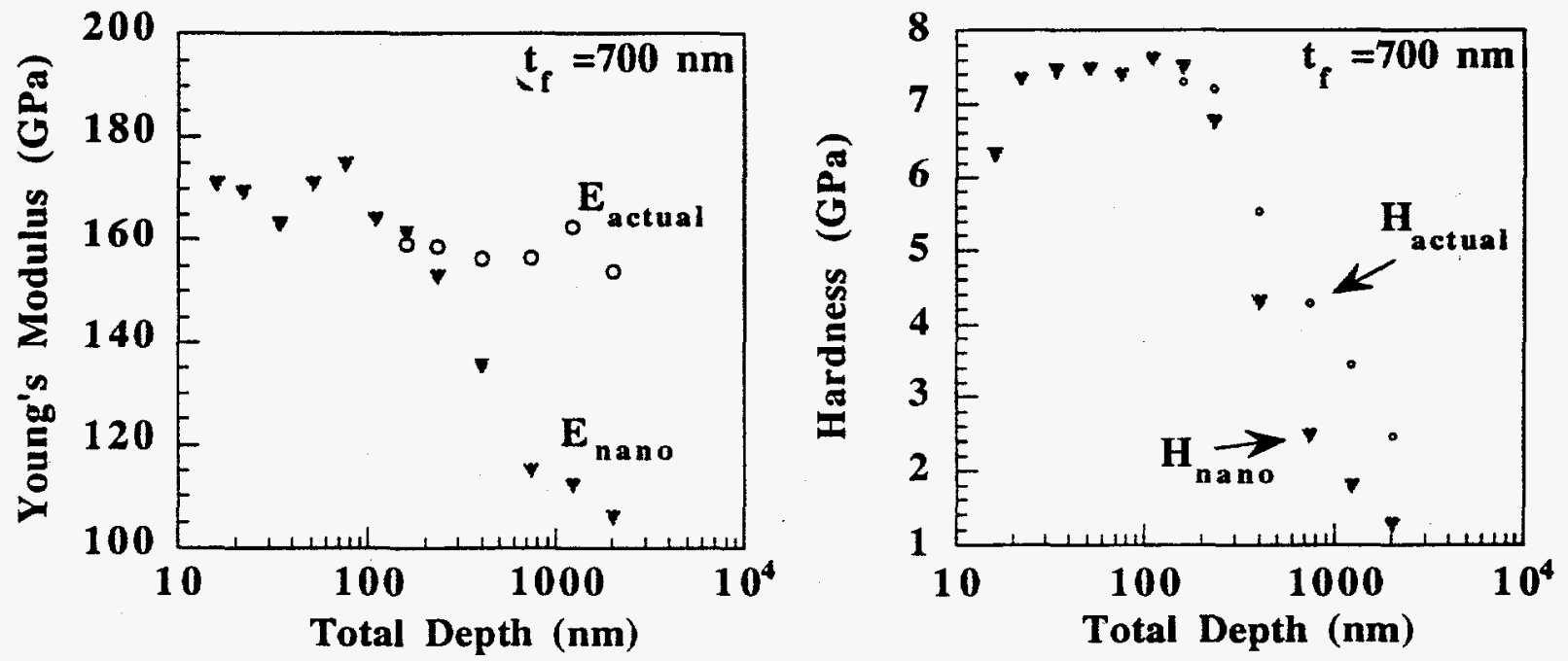

Figure 6. Comparison of Young's modulus and hardness of the $700 \mathrm{~nm}$ film based on the actual contact area measured by imaging and that determined by the Oliver-Pharr method (nano). 
An estimate of the true contact area for the impressions in the $700 \mathrm{~nm} \mathrm{NiP}$ film can be obtained from the images in Figure 4. This area can be used in Equations 1 and 2 to obtain id second measurement of the hardness and Young's modulus. In Figure 6, the Young's modulus and hardness evaluated with $A_{\text {actual }}$ are compared with the estimates, $H_{\text {nano }}$ and $E_{\text {nano }}$. Curiously, the Young's modulus, $E_{\text {actual }}$, does not decrease. Although it is not clear what the measured Young's modulus should be at $2000 \mathrm{~nm}$, it can be argued that it should be somewhere between the NiP value of $155 \mathrm{GPa}$ and the copper value of $129 \mathrm{GPa}$. There are two possible explanations for the unexpected behavior. First, the assumption has been made here that Sneddon's solution for indentation of an isotropic, homogeneous material applies to the film/substrate problem. The complex nature of elastic/plastic deformation in film/substrate systems may lead to violations of

this assumption. The second possibility is that the contact area determined from the SEM photographs represents a lower bound on the true contact area. An AFM trace along the line $i^{\prime}-i^{\prime}$ in Figure 5a reveals a high point along the center of the face indicated as the point $\mathrm{P}_{3}$. This implies that during unloading there may have been some elastic recovery along the faces. Therefore, contact areas from SEM photographs such as in Figure 4 may underestimate the actual contact area under load.

\section{ACKNOWLEDGMENTS}

This research sponsored in part by the Division of Materials Sciences, U.S. Department of Energy, under contract DE-AC05-960R22464 with Lockheed Martin Energy Research Corp., through the SHaRE Program under contract DE-AC05-76OR00033 with Oak Ridge Associated Universities, by an appointment (JCH) to the ORNL Postdoctoral Research Associates Program administered jointly by the Oak Ridge Institute for Science and Education and ORNL.

\section{REFERENCES}

1. J.B. Pethica, R. Hutchings, W.C. Oliver, Phil. Mag. A, 48, 593-606 (1983).

2. M.F. Doerner, W.D. Nix, J. Mater. Res., 1, 601 (1986).

3. W.C. Oliver, G.M. Pharr, J. Mater. Res., 7, 1564-1583 (1992).

4. S.V. Hainsworth, T. Bartlett, T.F. Page, Thin Solid Films, 236, 214-218 (1993).

5. T.F. Page, S.V. Hainsworth, Surface and Coatings Technology, 61, 201-208 (1993).

6. A.K. Bhattacharya, W.D. Nix, Int. J. Solids Structures, 24, 1287-1298 (1988).

7. P.J. Burnett, D.S. Rickerby, Thin Solid Films, 148, 51-65 (1987).

8. T.Y. Tsui, W.C. Oliver, G.M. Pharr, Mat. Res. Soc. Symp. Proc., 436, 207-212 (1997).

9. R.B. King, Int. J. Solids Structures, 23, 1657-1664 (1987).

10. H. Gao, C-H Chiu, J. Lee, Int. J. Solids Structures, 29, 2471-2492 (1992).

11. P.J. Burnett, D.S. Rickerby, Thin Solid Film, 148, 41-50 (1987).

12. D.S. Stone, J. Electronic Packaging, 112, 41-46 (1990).

13. I.N. Sneddon, Int. J. Engng. Sci., 3, 47-57 (1965).

14. L.E. Samuels, in Microindentation Techniques in Materials Science and Engineering, edited by P.J. Blau and B.R. Lawn (ASTM STP 889, ASTM, Philadelphia, 1986), p. 5.

15. P.M. Sargent, in Microindentation Techniques in Materials Science and Engineering, edited by P.J. Blau and B.R. Lawn (ASTM STP 889, ASTM, Philadelphia, 1986), p. 160.

16. R.W. Hertzberg, Deformation and Fracture Mechanics of Engineering Materials, (John Wiley \& Sons, New York, 1989), p. 7. 